\title{
EDITORIAL
}

\section{Spirometry performance in primary care: the problem, and possible solutions}

See linked articles by Levy et al.

on pg 130, Price et al. on pg 216,

Lucas et al. on pg 177, and

Poels et al. on pg 189

\section{*Christine Jenkins ${ }^{\mathrm{a}, \mathrm{b}}$}

a Head, Airways Group, Woolcock Institute of Medical Research, Sydney, Australia

b Senior Staff Specialist, Department of Thoracic Medicine, Concord Hospital, New South Wales, Australia

*Correspondence:

Professor Christine Jenkins, Department of Thoracic Medicine, Concord Hospital, Hospital Road, Concord, NSW 2139, Australia

Tel: +6129767 6712

Fax: +6129767 7605

E-mail: crj@med.usyd.edu.au
Despite universal agreement that the diagnosis and assessment of respiratory disease requires the accurate measurement of lung function, the simplest and most widely undertaken test - spirometry - continues to prove difficult to implement in primary care. This remains the case even though the last 10 to 15 years has seen the introduction of many affordable, reliable and portable desktop and hand-held spirometers which provide reference values and computer-generated interpretation of results and which are designed for easy use.

Multiple barriers exist in clinical practice to thwart the effective use of spirometry at all levels of outpatient care. ${ }^{1}$ These can be categorised as patient-related, practice-related and practitioner-related. From the patient's perspective there are numerous requirements for optimal performance, including maximal inspiration, maximal effort, and the absence of interfering factors such as chest pain, cough, poor lip seal, or variable effort. Practice-related problems include: the challenges of timing, particularly when bronchodilator reversibility testing is included; administering $\beta_{2}$-agonist; the unpredictable timing of when the test is required; the availability of trained personnel to perform spirometry; and the need to document any recent medication - particularly bronchodilators - for accurate interpretation. From the practitioner's point of view, any test must be undertaken with the confidence that it can be performed and interpreted reliably and that it will be a sensitive measure of the suspected clinical abnormality. In addition, it is essential that it can be interpreted without complicated caveats and major unresolved queries or uncertainties. Unfortunately, any one of these issues can affect the day-to-day performance of spirometry, and induce in practitioners a feeling that it really is not worth the effort.

Furthermore, spirometry is poorly reimbursed in many countries - a factor which provides no incentive for primary care physicians to overcome the challenges of incorporating spirometry into their daily practice. A fundamental misunderstanding - that spirometry is a simple test requiring minimal skill - is perhaps an unfortunate historical consequence of the apparent simplicity of bellows spirometers and the extrapolation that spirometry is an easy test to perform and interpret. In the difficult environment of general practice - where there are substantial pressures to see large numbers of patients efficiently - a cumbersome test which is difficult to interpret, poorly reimbursed, and not clearly related to achieving better clinical outcomes, is unlikely to be widely adopted.

Yet there is no substitute for spirometry, even though in countries where it is not widely available a standardised clinical algorithm or diagnostic pathway can greatly assist in diagnosing common airway diseases. ${ }^{2}$ Spirometry is essential for diagnosing obstructive lung disease accurately, assessing its severity, determining and measuring response to treatment, and tracking patients' progress over time. In addition, as Price et al. discuss in this issue, ${ }^{3}$ screening spirometry could be used for systematic case-identification of patients who might have chronic obstructive pulmonary disease (COPD). When well performed, spirometry is also essential for ruling out significant airways disease, and avoiding overdiagnosis. What then are the solutions to narrow the gap between theory and practice in relation to primary care spirometry?

There is probably no single answer, and almost certainly we have focused too much on the hope that implementing effective spirometry in primary care is most readily achieved by 
training general practitioners (GPs). Recently, several different models of implementing spirometry have been trialled - two of which are reported in this issue of the $P C R J^{4,5}$ - and it is clear that there are many potential solutions to the problem. These include: training practice nurses; providing a visiting spirometry team; strengthening referral to local respiratory services; instituting quality performance and control through centralised monitoring; and using chest physician review or inbuilt software interpretation. ${ }^{4-9}$

For those primary care physicians and nurses who wish to master the skill of spirometry and use it more widely in assessing patients with breathlessness, the Standards Document on diagnostic spirometry in primary care by Levy et al. in this month's journal ${ }^{10}$ provides an excellent resource and a practical manual that should help greatly in the day-to-day performance of spirometry. Many online resources are now available, but most would agree that a handbook or guideline for optimal spirometry performance is an indispensable aid to learning and maintaining spirometry skills and troubleshooting when problems arise. This is particularly the case when a guideline is written from a primary care perspective - such as this one ${ }^{10}$ - by clinicians who are committed to maintaining high quality respiratory diagnosis and care, and who undertake to update the document regularly. A feedback and evaluation process, or trials of implementation of spirometry using this document, with ongoing clinical audit, would make this updating and revision most valuable.

This document also strongly advocates the wider availability of training in spirometry, including opportunity for assessment and demonstration of ongoing competence. ${ }^{10}$ Professional societies, advocacy organisations and better practice initiatives funded at health department level should collaborate to provide high quality training that is readily accessible and minimally demanding of practitioner time. Web-based training with expert review, as well as hands-on workshops, should be available to promote optimal uptake and implementation of spirometry in primary care. Finally, inclusion of spirometry training in undergraduate education as a major learning objective - rather than as an optional aside in respiratory curricula - should help to ensure that spirometry is regarded as a procedure that can be mastered and integrated appropriately into optimal respiratory diagnosis and care in general practice.

\section{Conflict of interest declaration}

No conflicts of interest to declare.

\section{References}

1. Eaton T, Withy S, Garrett JE, Mercer J, Whitlock RML, Rea HH. Spirometry in primary care practice. The importance of quality assurance and the impact of spirometry workshops. Chest 1999;16:416-23. http://dx.doi.org/10.1378/ chest.116.2.416

2. Calverley PM., Nordyke RJ, Halbert R J, Isonaka S, Nonikov D. Development of a population-based screening questionnaire for COPD. COPD 2005;2:225-32. http://dx.doi.org/10.1081/COPD-200057594

3. Price $D$, Crockett $A$, Arne $M$ et al. Spirometry in primary care caseidentification, diagnosis and management of COPD. Prim Care Resp J 2009; 18(3):216-23. http://dx.doi.org/10.4104/pcrj.2009.00055

4. Lucas AEM, Smeenk FJWM, van den Borne BEEM, Smeele IJM, van Schayck OCP. Diagnostic assessments of spirometry and medical history data by respiratory specialists supporting primary care: are they reliable ? Prim Care Resp J 2009;18(3):177-84. http://dx.doi.org/10.3132/pcrj.2009.00002

5. Poels PJP, Schermer TRJ, Thoonen BPA et al. Spirometry expert support in family practice : a cluster-randomised trial. Prim Care Resp J 2009;18(3):189-97. http://dx.doi.org/10.4104/pcrj.2009.00047

6. Burton MA, Burton DL, Simpson MD, Gissing PM, Bowman SL. Respiratory function testing: the impact of respiratory scientists on the training and support of primary health providers. Respirology 2004;9:260-4.

7. Walters JA, Hanson EC, Johns DP, Blizzard EL, Walters EH, Wood-Baker R. A mixed methods study to compare models of spirometry delivery in primary care for patients at risk of COPD. Thorax 2008;63:408-14. http://dx.doi.org/ $10.1136 /$ thx.2007.082859

8. Poels PJP, Schermer TRJ, Schellekens DPA et al. Impact of a spirometry expert system on general practitioner's decision making. Eur Respir J 2008;31:84-92. http://dx.doi.org/10.1183/09031936.00012007

9. Walker PP, Mitchell, Diamentea F, Warburton CJ, Davies L. Effect of primarycare spirometry on the diagnosis and management of COPD. Eur Respir J 2006; 28:945-52. http://dx.doi.org/10.1183/09031936.06.00019306

10. Levy ML, Quanjer PH, Booker R, Cooper BG, Holmes S, Small IR. Diagnostic Spirometry in Primary Care. Proposed standards for general practice compliant with American Thoracic Society and European Respiratory Society recommendations. Prim Care Resp J 2009;18(3):130-47. http://dx.doi.org/10.4104/pcrj.2009.00054

\section{Available online at http://www.thepcrj.org}

